\section{Exploring a "Splendid and Delightsome" Land: Research on the 17th Century Chesapeake}

\author{
EDITED BY HENRY M. MILLER, HISTORIC \\ ST. MARY'S CITY; JULIA A. KING, \\ JEFFERSON PATTERSON PARK AND \\ MUSEUM
}

\section{Preface}

Since the early 1970's, study of the 17th century Chesapeake colonies of Maryland and Virginia has undergone a renaissance. The efforts of historians and archaeologists were directed to exploring this poorly known place and time and their findings are significantly altering perceptions of the region's early history. Today, Chesapeake research is a dynamic and maturing field of inquiry and the papers in this number illustrate various aspects of this scholarly effort.

The first paper by Riordan reports the methods and results of studying surface evidence from colonial sites in St. Mary's City. It demonstrates that valuable insights may be obtained from surface collected materials, ranging from the spatial layout of sites to inferences about the architectural form of long vanished structures. Perhaps of greatest value, however, is Riordan's demonstration that the extraordinary amount of important cultural data present in the plowzone is reflected even in the tiny proportion of materials which appear on the surface. This finding implies that if the potential of yielding important cultural and historical insight is the criterion for nomination to the National Register, then sites are eligible on the basis of their plow zone data alone: intact sub-surface features are not necessary for a site to be considered significant.

King and Pogue focus upon the evidence extracted from the plowzone by excavation. King addresses the important question of how site function influences the spatial distribution of archaeological materials. Her comparison of artifact pat- terns from a private dwelling and public inn reveals the need for more high-quality data from a variety of sites if spatial behavior is to be deciphered. Pogue provides an important comparative example with his study of the Kings Reach site. This is one of the few plantation sites occupied for a short time period to be reported from the Chesapeake. Its spatial analysis shows the complexity of artifact patterning, even on a site inhabited only for one or two decades.

Miller reports the discovery of a previously unsuspected city plan for Maryland's first capital. This finding, based upon archaeological evidence, has important implications for Maryland history and the study of urban design in early America. In addition, it raises significant questions about the influence of social and economic factors on the form of urban places.

Finally, the subject of material culture and living standards is addressed by English historian James Horn. He addresses the question of how New World immigration affected living standards by comparing architectural and probate inventory evidence from England and the Chesapeake. Horn focuses upon perishable material possessions like furniture which archaeologists rarely recover, but which were integral to daily life in the 17th century. The findings indicate how austere colonial life was in comparison to England. At the same time, Horn's research points out how complementary archaeological and historical data can be and suggests important areas of cooperation. For example, he can evaluate the ownership patterns of furniture and clothing, but cannot adequately assess subjects such as diet, the nature of health and hygiene, or ceramic and glassware usage without archaeological information. These subjects are equally significant in appraising changing living standards.

One future direction of Chesapeake research will almost certainly be the integration of data from documentary and archaeological sources to produce broader, holistic analyses of colonial society. This will, in turn, permit more sophisticated comparative research between the various American colonies and with England. 